\title{
PENGARUH LATIHAN BOLA GANTUNG TERHADAP KEMAMPUAN SMASH KEDENG DAN SMASH GULUNG DALAM PERMAINAN SEPAK TAKRAW PADA ATLET PSTI KABUPATEN LEBONG
}

\author{
Addriyal Pernandes \\ PJKR FKIP UNIB, e-mail: addriyalpernandes@gmail.com \\ Ari Sutisyana \\ Universitas Bengkulu
}

\begin{abstract}
Abstrak
Penelitian ini bertujuan untuk mengetahui peningkatan kemampuan smash kedeng dalam permainan sepak takraw setelah diterapkan latihan otot tungkai menggunakan bola gantung. Jenis penelitian kuantitatif yang bersifat eksperimen dimana terdapat perlakuan pada objek penelitian dengan menggunakan desain penelitian pre test, perlakuan, post test dengan populasi penelitian 30 atlet laki-laki dengan penarikan sampel dalam total sampling sebanyak 30 atlet PSTI Kabupaten Lebong. Hasil tes akhir diperoleh korelasi yang dihitung dengan menggunakan rumus product moment diperoleh pre test dan post test latihan otot tungkai dengan menggunakan bola gantung dengan $r=0,574$, hasil korelasi post test latihan bola gantung dengan $r=0,349$, hasil korelasi dari hitungan pre test dan post test smash kedeng dengan $r=0,4407$. Dan disimpulkan bahwa terdapat pengaruh yang signifikan antara latihan otot tungkai menggunakan bola gantung selama 1 bulan $2 \mathrm{minggu}$ dengan $3 \mathrm{kali} / \mathrm{minggu}$ terhadap kemampuan smash kedeng adalah sebesar $59,65 \%$.
\end{abstract}

Kata kunc: Latihan Bola Gantung, Peningkatan Smash kedeng dan Smash Gulung.

\begin{abstract}
This study aims to determine the improvement of the ability of smash kedeng in game sepak takraw after applied leg muscle exercises using hanging balls. The type of quantitative research is experimental in which there is treatment on the object of research by using pre-test research design, treatment, post test with a population of 30 male athletes with sampling in total sampling of 30 athletes PSTI Lebong District. The final test results obtained correlation calculated by using product moment formula obtained by pre test and post test of leg muscle by using hanging ball with $r=0,574$, result of post test correlation of hanging ball with $r=0,349$, correlation result from pre test and post Test smash kedeng with $r=0.4407$. And concluded that there is a significant influence between leg muscle exercise using a hanging ball for 1 month 2 weeks with 3 times / week on the ability to smash kedeng is equal to $59.65 \%$.
\end{abstract}

Keyword: Limb muscle training, Improved, Smash kedeng and Smash Gulung. 


\section{PENDAHULUAN}

Dalam kehidupan yang serba modern seperti sekarang ini olahraga dipandang sebagai kebutuhan yang sangat penting, karena olahraga mempunyai manfaat untuk menjaga kondisi fisik seseorang dan merupakan salah satu alternatif untuk tujuan meningkatkan kesehatan dalam rangka untuk tujuan meningkatkan kualitas hidup manusia. Oleh karena itu olahraga sangat berperan dalam meningkatkan kualitas manusia seutuhnya yakni sehat jasmani dan rohani, berdisiplin tinggi dan berjiwa sportifitas.

Untuk meningkatkan prestasi olahraga, maka pembinaan prestasi olahraga perlu dilakukan melalui perencanaan dan pelaksanaan yang baik serta dilaksanakan secara terpadu dan merata di seluruh tanah air. Hal ini dilakukan bukan hanya oleh pemerintah, akan tetapi juga perlu didukung oleh berbagai pihak.

Pembinaan dan pengembangan olahraga sudah menjadi tanggung jawab bersama dimulai dari pusat, hingga ke daerah-daerah melalui induk organisasi yang ada guna pencapaiaan prestasi yang maksimal, diantaranya prestasi olahraga Sepak Takraw. Salah satu dari pembinaan prestasi olahraga Sepak Takraw di Provinsi Bengkulu adalah PSTI Kabupaten Lebong yang berdiri pada tanggal 07 Juni 1997.

Pada tahun 2003 mulai bermunculan turnamen dalam daerah dimana atlet PSTI Kabupaten Lebong turut serta dalam turnamen tersebut. Pada saat itu PSTI Kabupaten Lebong mulai ramai kedatangan atlet-atlet yang ingin bergabung dalam pembinaan. Sampai saat ini PSTI kabupaten Lebong banyak dikenal atas prestasiprestasinya di tingkat daerah maupun tingkat nasional. hal ini menyebabkan bertambahnya atlet putra binaan yang bergabung di PSTI Kabupaten Lebong sebanyak 30 orang.

Berdasarkan hasil wawancara dengan pelatih harian di PSTI Lebong diketahui bahwa banyak kekurangan dalam melakukan smash dan masih sedikit para atlet yang minat dalam posisi smash dikarenakan kurangnya pengetahuan dan pembelajaran dari pelatih dan senior. Seperti diketahui smash sendiri memiliki pengaruh yang sangat penting dalam mendapatkan point pada saat proses permainan.

Menurut Jamalong dan Syam (2014:6) "dalam permainan Sepak Takraw terdapat beberapa jenis teknik, yaitu teknik dasar dan teknik khusus. Teknik dasar terdiri dari sepakan, heading, mendada, memaha, dan membahu. Teknik khusus terdiri dari melambungkan bola ke tekong, sepak mula, menerima sepak mula, serangan (smash) dan membendung (block). Untuk menunjang kemampuan individu diperlukan skill individu yang berkelanjutan dengan cara pendalaman teknik khusus. Diantara beberapa teknik khusus yang paling berpengaruh adalah smash. Peranan smash dianggap berpengaruh karena penggunaan smash yang baik dan benar dapat mempengaruhi mental lawan sehingga dapat mematikan bola didaerah lawan. Hal ini sejalan dengan Jamalong dan Syam (2014:36) yang mengemukakan bahwa tujuan smash adalah untuk mematikan bola di daerah lawan dan selanjutnya memberikan kesempatan server kawan melakukan service. .

Salah satu teknik kemampuan smash adalah smash kedeng. Menurut Darwis dan Penghulu (1992: 69) dalam Eka dan Sudarso (2015:141-142) smash kedeng merupakan 
smash yang dilakukan dengan menggunakan kaki, untuk itu pemain apit kiri dan apit kanan yang mempunyai banyak kesempatan untuk melakukan smash dalam menyerang lawan perlu dilatih dengan baik agar mempunyai kemampuan atau skill smash yang baik. Dalam sepak takraw juga smash kedeng merupakan faktor penting dalam pola serangan, yang mencakup semua untuk keterampilan dasar yang harus dikuasai oleh pemain. Berdasarkan pengamatan terhadap atlet smash kedeng belum memadai hal itu diketahui dari hasil tes latiahan otot tungkai Anwar, (1999:28) dalam Yuwono, dkk (2006:41).

Dalam hal ini belum diketahuinya kecermatan pada smash kedeng serta para pelatih ingin mengetahui kemampuan smash kedeng pada atlet. Hal ini dilakukan agar dapat meningkatkan hasil dari kemampuan smash kedeng para atlet untuk mencapai hasil smash kedeng yang baik dan meningkatkan hasil prestasi atlet.

Berkenaan hal tersebut diatas maka penulis tertarik untuk melakukan penelitian "Pengaruh Latihan Otot Tungkai Terhadap Smash Kedeng dalam Permainan Sepak Takraw pada Atlet PSTI Kabupaten Lebong".

\section{METODE}

Desain yang digunakan dalam penelitian ini adalah One group pretestposttest design. Pada desain ini terdapat pretest sebelum diberi perlakuan dengan demikian hasil perlakuan dapatdiketahui lebih akurat, karena dapat membandingkan dengan keadaan sebelum diberi perlakuan Sugiyono (20014: 75) Dalam pengambilan data peneliti menggunakan tes dan pengukuran, digunakan adalah tes keterampilan smash kedeng oleh M. Husni
Thamrin (2008:15) dalam Richy Nuur Huda (2015:55). Prosedur pelaksanaan :

1) Teste dikumpulkan dan diberi penjelasan mengenai pelaksanaan tes yang akan dilakukan, kemudian melakukan pemanasan selama 15 menit.

2) Teste dipangil satu persatu sesuai dengan urutannya untuk memasuki lapangan sepak takraw.

3) Testor memberi aba-aba "mulai", kemudian teste melakukan smash kedeng di depan net dengan bola dilempar atau dilambungkan sendiri.

4) Setiap teste melakukan smash 5 kali smash kedeng, di arahkan kelapangan yang telah ditandai dengan angka-angaka (nilai). Waktu istirahat testi adalah saat menunggu giliran melakukan smash pada percobaan berikutnya.

5) Testor mencatat skor dan mengambil nilai yang tertinggi dari 5 kali melakukan smash kedeng.

\section{Pelaksanaan tes:}

1) Testee mengambil tempat di depan net dan siap melakukan smash

2) Bola dilambungkan ke arah testee berdasarkan ketinggian yang dihendaki dekat net

3) Testee akan melompat dan melakukan smash melewati dam melakukan smash melewati atas net ke lapangan lawan.

4) Setiap testee diberi kesempatan melakukan lima kali smash 


\section{HASIL DAN PEMBAHASAN}

HASIL

Dari hasil tes awal smash kedeng pada atlet PSTI Kabupaten Lebong maka dapat disimpulkan bahwa dari 30 atlet sebanyak 8 atlet $(33,33 \%)$ dalam kategori nilai 3,00-4,02, sebanyak 7 atlet (20\%) dalam kategori 4,03-5,05, sebanyak 4 atlet $(13,33 \%)$ dalam kategori 5,06-6,08, sebanyak 4 atlet $(16,67 \%)$ dalam kategori 6,09-7,11, sebanyak 4 atlet $(6,667 \%)$ dalam kategori 7,12-8,14, sabanyak 3 atlet (10\%) dalam kategori 8,15-9,17, berdasarkan data tersebut mean atau rata-rata 5,567.

Setelah pemberian metode latihan otot tungkai dengan menggunakan bola gantung hasil tes akhirnya Dari ttabel diatas maka dapat disimpulkan bahwa dari 30 atlet sebanyak 3 atlet (10\%) dalam kategori nilai 6,0-7,4, sebanyak 7 atlet (23,33\%) dalam kategori 7,5-8,9, sebanyak 13 atlet $(46,67 \%)$ dalam kategori 9,0-10,4, sebanyak 2 atlet $(3,33 \%)$ dalam kategori $10,5-11,9$, sebanyak 4 atlet (13,33\%) dalam kategori 12,0-13,4, sabanyak 1 atlet (3,33\%) dalam kategori 13,5-14,9, berdasarkan data tersebut mean atau rata-rata 9,333 .

Hasil uji normalitas pada Atlet PSTI Kabupaten Lebong disajikan dalam tabel ini:

\begin{tabular}{l|l|l|l} 
Data Penelitian & $\chi_{\text {hitung }}^{2}$ & $\chi^{2}{ }_{\text {tabel }}$ & Kesimpulan \\
\hline $\begin{array}{l}\text { Sebelum } \\
\text { Pelatihan }\end{array}$ & 8,8697 & 9,488 & Normal \\
\hline $\begin{array}{l}\text { Sesudah } \\
\text { Pelatihan }\end{array}$ & 8,1062 & 9,488 & Normal \\
\hline
\end{tabular}

Tabel diatas menunjukkan bahwa data smash kedeng Atlet sebelum dan sesudah diberi latihan berdistribusi normal.
Hal ini ditunjukkan dari hasil perhitungan menunjukkan bahwa data penelitian memiliki nilai $\chi_{\text {hitung }}^{2}<\chi_{\text {tabel }}^{2}$. Nilai $\chi_{\text {hitung masing-masing data adalah }}^{2}$ sebesar 8,8697 dan 8,1062 dan kurang dari $\chi_{\text {tabel }}^{2}=9,488$.

Uji homogenitas dilakukan untuk mengetahui apakah semua data hasil penelitian merupakan data yang homogen atau tidak. Uji homogenitas dalam penelitian ini dilakukan menggunakan uji $F$. Adapun hipotesis yang diuji adalah: tidak terdapat pengaruh antara data sebelum dan sesudah diberikan pelatihan.

Kriteria pengujian yang digunakan dalam penelitian ini adalah data berdistribusi homogen jika nilai $F_{\text {hitung }}<F_{\text {tabel. }}$. Hasil uji homogenitas data penelitian menunjukkan bahwa nilai $F_{\text {hitung }}=1,022$ dan $<$ dari $F_{\text {tabel }}=3,340$. Sehingga data homogen.

Setelah diketahui bahwa data yang diperoleh dari penelitian memenuhi uji prasyarat yaitu berdistribusi normal dan homogen, selanjutnya dilakukan pengujian hipotesis. Pengujian hipotesis dalam penelitian ini menggunakan analisis statistik uji $\mathrm{t}$ (independent sampel t-test). Hasil analisis uji $\mathrm{t}$ digunakan untuk melihat pengaruh latihan yang diberikan terhadap smash kedeng Atlet. Perhitungan dilakukan dengan membandingkan antara smash kedeng sebelum dan sesudah diberikan perlakuan. Adapun hipotesis statistik penelitian yang diuji asebagai berikut: 


\section{$\mathrm{H}_{0}: \quad \mu_{1}=\mu_{2}$ (Tidak terdapat perengaruh antara smash kedeng Atlet sebelum dan sesudah diberikan pelatihan) \\ $\mathrm{H}_{1}: \quad \mu_{1} \neq \mu_{a}$ ( terdapat pengaruh antara smash kedeng Atlet sebelum dan sesudah diberikan pelatihan )}

Dari hasil tes-tes diatas dapat dilihat bahwa terdapat pengaruh antara variabel latihan otot tungkai dengan menggunakan bola gantung terhadap kemampuan smash kedeng, terdapat pengaruh yang cukup signifikan dengan t hitung $>$ dari t table yaitu $8,278>2,001$.

\section{Pembahasan}

Dari penelitian ini bertujuan melihat pengaruh dari satu kelompok yang diberikan perlakuan (eksperimen) latihan otot tungkai dalam penelitian ini menggunakan total sampling adalah mengambil sebagian dari keseluruhan. Maka dari itu dari keseluruhan atlet PSTI Kabupaten Lebong diambil sebagiannya untuk menjadi sampel dalam penelitian ini. Desain yang digunakan dalam penelitian ini adalah one group pretestposttest design dengan kata lain design ini menggunakan dua kali pengambilan data yaitu dengan melakukan tes awal dan tes akhir.

Dapat diketahui bahwasanya ada kajian sebagai acuan metode penelitian Sianlipon Sukel (2009) dengan judul "Pengaruh latihan kekuatan otot tungkai terhadap kemampuan smash dalam permainan sepak takraw mahasiswa FIK Unima" dengan ditinjau dari data penelitian ini maka dapat di dapat hipotesis $\left(\mathrm{H}_{\mathrm{A}}\right)$ diterima, dengan demikian rata-rata latihan kekuatan otot tungkai mahasiswa FIK UNIMA setelah diberikan program latihan selama dua bulan dengan frekuensi tiga kali seminggu lebih baik dari pada rata-rata latihan kekuatan otot tungkai mahasiswa sebelum latihan. Oleh sebab itu hasil penelitian ini dapat disimpulkan bahwa program latihan kekuatan otot tungkai selama dua bulan dengan frekuensi tiga kali seminggu mempunyai pengaruh terhadap kemampuan smash dalam permainan sepak takraw mahasiswa FIK UNIMA, atau dapat dikatakan bahwa program latihan kekuatan otot tungkai memberikan pengaruh yang signifikan untuk meningkatkan kemampuan smash dalam permainan sepak takraw pada mahasiswa FIK UNIMA.

Pada penelitian ini dapat dilihat dan sebagai penguat atau acuan bahwa pada tes awal penelitian (Pre test) yang telah dilakukan menunjukkan bahwa kemampuan smash kedeng dari para atlet laki-laki pada penelitian ini nilai terendah 3 dan nilai tertinggi dengan nilai 9 dari nilai tes awal ini dapat diperoleh nilai rata-rata 5,567. Pada tes akhir (Post test) yang telah dilakukan menunjukkan bahwa kemampuan smash kedeng meningkat dari pada atlet laki-laki pada penelitian ini nilai terendah 6 dan nilai tertinggi dengan nilai 14 dari nilai tes awal ini dapat diperoleh nilai rata-rata 9,333. Berdasarkan hasil penelitian yang telah dilakukan nilai rata-rata kemampuan smash kedeng sebelum di beriperlakuan dan setelah di beriperlakuan terdapat pengaruh.

Dari diagram yang telah disajikan sebelumnya dapat dijelaskan bahwa dalam memberikan perlakuan dengan latihan otot tungkai menggunakan bola gantung selama 1 bulan 2 minggu dengan 3 kali /minggu, peningkatan smash kedeng sebesar $59,65 \%$ Untuk menentukan peningkatan smash kedeng digunakan untuk mengetahui kemampuan fisik adalah tes smash kedeng 
dengan 5 kali percobaan. Bentuk tes ini mempunyai beberapa kelebihan, diantaranya data yang diperoleh valid dan dapat dilaksanakan secara massal.

Dari hasil pre test dan post test dapat diketahui seberapa besar nilai kemampuan smash kedeng dalam klasifikasi kurang, sangat kurang, sedang, baik dan baik sekali untuk para Atlet PSTI Kabupaten Lebong. Dari 30 atlet secara keseluruhan dalam klasifikasi sedang. Kemampuan smash kedeng sangat kurang sebanyak 16 orang sedangkan untuk klasifikasi kurang sebanyak 11 orang dan untuk kalsifikasi sedang sebanyak 3 orang. Dilihat dari persentase rata-rata pre test dan post test terjadi peningkatan secara signifikan sebesar $59,65 \%$.

Smash kedeng dalam sepaktakraw merupakan aspek penting dalam permainan sepak takraw, yaitu kemampuan keterampilan khusus. Dalam latihan keterampilan smash kedeng dalam permainan sepaktakraw, hal terpenting adalah membiasakan mahasiswa agar dapat melakukan smash pada situasi bermain sepaktakraw sesungguhnya. Latihan dengan bola gantung bisa lepas mempunyai maksud untuk memberikan pembelajaran keterampilan teknik dalam situasi permainan sesungguhnya sehingga seorang pemain dapat meningkatkan ketrampilan smash kedeng. Dengan latihan bola gantung bisa lepas, mempermudah mahaiswa dalam melakukan smash kedeng karena bola digantung sehingga setiap individu bisa menentukan ketinggian bola sesuwai dengan kemampuannya, koordinasi antara indera penglihat dan indera gerak yang didukung oleh posisi badan yang memungkinkan maka dapat menghasilkan koordinasi yang baik antara keduanya, Seorang pemain dapatmenentukan ketepatan antara perkenaan bagian kaki dengan bola pada saat melakukan smash, dapat memotivasi jangkauan pukulan yang lebih tinggi, memberikan kesenangan dalam aktivitas latihan dan dapat meningkatkan keterampilan teknik Richy Nuur Huda (2015).

Berdasarkan hasil pengujian hipotesis yang telah dilakukan sebelumnya menyatakan bahwa ada pengaruh yang signifikan antara latihan otot tungkai terhadap kemampuan smash kedeng Atlet PSTI Kabupaten Lebong dapat disimpulkan bahwa semakin sering melakukan latihan tersebut maka semakin baik pula peningkatan kemampuan smash kedeng. Berdasarkan data penelitian ini terdapat pengaruh dari post test latihan otot tungkai dengan menggunakan bola gantung dan post test smash kedeng pada Atlet PSTI Kabupaten Lebong sebesar $11,68 \%$ dapat disimpulkan bahwa semakin sering melakukan latihan tersebut maka semakin baik pula peningkatan smash kedeng dan smash gulug atlet tersebut.

\section{PENUTUP}

\section{Kesimpulan}

Sinalipon Sukel (2009) yang berjudul "Pengaruh Latihan Kekuatan Otot Tungkai Terhadap Kemampuan Smash Dalam Permainan Sepak Takraw" dari hasil penelitian ini dapat disimpulkan Hasil penelitian menunjukkan bahwa pengujian uji-thitung $=4.01$ lebih besar dari $t_{\text {tabel }}=2,021$, sehingga kesimpulannya menolak hipotesis statistik $\left(\mathrm{H}_{0}\right)$ dan menerima hipotesis $\left(\mathrm{H}_{\mathrm{A}}\right)$

Berdasarkan pada hasil pembehasan dan penelitian ini serta dari pengolahan data yang telah dilakukan maka dapat simpulkan 
klasifikasi kemampuan smash kedeng pada Atlet PSTI Kabupaten Lebong setelah diberikan latihan otot tungkai dengan menggunakan bola gantung dapat di kategorikan kurang dan sedang. Klasifikasi untuk Atlet dengan kategori kurang sebanyak 23 ( 76,67 \% ) Orang sedangkan untuk kategori sedang sebanyak 7 ( 23,33 \%) orang, Besarnya pengaruh latihan otot tungkai dengan menggunakan bola gantung meningkat sebesar $59,65 \%$ berdasarkan hasil penelitian yang telah dilakukan sebelumnya menyatakan bahwa ada pengaruh yang cukup signifikan antara latihan otot tungkai terhadap kemampuan smash kedeng atlet PSTI kabupaten lebong dapat disimpulkan latihan otot tungkai sangat berpengaruh dalam melakukan smash kedeng, semakin sering melakukan latihan otot tungkai maka semakin baik pula kemapuan smash kedeng.

\section{Saran}

Berdasarkan hasil penelitian yang telah diuraikan sebelumnya maka peneliti memberikan saran diantaranya sebagai berikut:

1. Diharapkan bagi para pembina dan pelatih agar dapat memberikan program latihan yang baik sebagai upaya untuk meningkatkan kemampuan smash kedeng.

2. Para atlet diharapkan dapat disiplin dalam latihan agar memiliki kemampuan yang baik dalam permainan sepak takraw.

3. Untuk peneliti lain disarankan agar dapat menentukan latihan yang tepat untuk meningkatkan pengaruh yang lebih besar kepada para atlet.

\section{DAFTAR PUSTAKA}

Annas, Muhammad. (2014). "Pengaruh Latihan Smash Kedeng Menggunakan Area Bertahap Terhadap Keterampilan Smes Sepaktakraw". Journal Of Physical Education, Health And Sport, $1(1):(35-40)$

Arikunto, Suharsimi. (2009). Dasar-Dasar Evaluasi Pendidikan. Jakarta: Bumi Aksara

Arikunto, Suharsimi. (2010). Prosedur Penelitian suatu Pendekatan Praktik. Jakarta: Rineka Cipta

Harsono. (1988). Coaching Dan AspekAspek Psikologi Dalam Coaching. Jakarta: CV. Tambak Kusuma.

Iyakrus. (2012). Permainan Sepak Takraw. Palembang : Unsri Press.

Jamalong, Ahmad dan Syam, Arsy. (2014). Teknik Dasar Permainan Sepak Takraw. Yogyakarta : Ombak.

Pratama, Wisnu. (2015). Pengaruh Latihan Bola Gantung Terhadap Hasil Smash Kedeng Sepak Takraw Pada Siswa Putra Ekstrakurikuler Sekolah Menengah Atas Negeri 1 Pemulutan Barat. Artikel Ilmiah, 1-11.

Sugiyono. (2014). Metode Penelitian Kuantitatif Kualitatif dan $R \& D$. Bandung: Alfabeta.

Syahputra, Andi. (2014). Perbedaan Pengaruh Latihan Bola Gantung dan Latiahan Bola Diumpan Terhadap Hasil Smash Kedeng Pada Atlet PSTI Tunas Mandiri Pantai Cermin. Skripsi. Medan: Universitas Negeri Medan. 
Tangkudung, James. (2012). Kepelatihan Olahraga Pembinaan Prestasi Olahraga. Jakarta: Cerdas jaya ,(2016).Macam-macam Metodologi Penelitian. Jakarta: Lensa Media Pustaka Indonesia

Yuwono, dkk. (2015). "Latihan Split Jump dan Knee Tuck Jump Untuk Meningkatkan Power Otot Tungkai dan Kemampuan Melakukan Smash Kedeng". Journal of Sport Sciences and Fitnes, 4 (3) 